\title{
Dampak Abrasi Pulau Tiban, Desa Kartikajaya Kecamatan Patebon Kabupaten Kendal
}

\author{
Distira Andy Liawan', Mahmud Abdul Haris ${ }^{2}$ \\ ${ }^{12}$ Program Studi Teknik Sipil, Fakultas Teknik dan Rekayasa, Universitas Selamat Sri \\ Email: ${ }^{1}$ distiraandy@gmail.com
}

\begin{abstract}
In mid-2017 there was a fairly large storm on the north coast of Java which resulted in quite a large amount of coastal abrasion in the tourist attraction "Pulau Tiban" Kartikajaya Village, Patebon District, Kendal Regency, so that tourism activities stopped. This research aims to determine the process of abrasion and the impact felt by the surrounding community due to the destruction of the tourist attraction "Pulau Tiban" in Kartikajaya Village. While the method used is observation with remote sensing methods, namely using the Google Earth application to determine the level of abrasion process from year to year and interviews to determine the impact of abrasion on tourist attraction activities. From the observations, it can be seen that sedimentation and accretion occurred from 2013 to 2017, experiencing a significant increase, reaching a maximum area of more than 8.2 hectares with an annual average of 1.27 hectares. Meanwhile, the abrasion that occurred in the 2017 to 2019 period and almost submerged the "Pulau Tiban" Beach Tourism Object of 2.5 halyear. With the SPSS 26.0 application in 2020, the level of validity can be seen by comparing $r$ count with Sig 1-tailed, data validity is seen if $r$ count $\geq$ Sig.1-tailed with a significance of 0.05 or $5 \%$. To find $r$ table, where $d f=N-2$ then $r$ table is 0.3172 while the value of the sample question gets the value of $r$ count $=0.778$ which is greater than the value of $r$ table $=0.3172$ so that the question is said to be valid.
\end{abstract}

Keywords: Abrasion, Google Earth, Validity, SPSS, Impact.

\begin{abstract}
Abstrak
Pada pertengahan tahun 2017 terjadi badai yang cukup besar di pantai utara Jawa yang mengakibatkan abrasi pantai cukup besar di objek wisata "Pulau Tiban" Desa Kartikajaya Kecamatan Patebon Kabupaten Kendal, sehingga aktifitas kepariwisataan menjadi terhenti. Adapun penelitian ini bertujuan untuk mengetahui proses terjadinya abrasi dan dampak yang di rasakan masyarakat sekitar akibat hancurnya objek wisata "Pulau Tiban" Desa Kartikajaya. Sedangkan metode yang digunakan adalah observasi dengan metode penginderaan jauh yaitu menggunakan aplikasi Google Earth untuk mengetahui proses tingkat abrasi dari tahun ke tahun dan wawancara untuk mengetahui dampak abrasi terhadap kegiatan objek wisata. Dari hasil pengamatan dapat diketahui sedimentasi dan akresi terjadi sejak tahun 2013 sampai tahun 2017 mengalami peningkatan yang cukup besar hingga mencapai luas maksimal lebih dari 8,2 hektar dengan ratarata per tahun 1.27 hektar. Sedangkan abrasi yang terjadi dalam rentang waktu 2017 sampai dengan 2019 dan hampir menenggelamkan Objek Wisata Pantai "Pulau Tiban" sebesar 2.5 ha/tahun. Dengan aplikasi SPSS 26.0 tahun 2020 dapat diketahui tingkat validitas dengan membandingkan $\mathrm{r}$ hitung dengan Sig 1-tailed, validitas data dilihat jika $\mathrm{r}$ hitung $\geq$ Sig.1- tailed dengan signifikansi 0,05 atau 5\%. Untuk mencari $\mathrm{r}$ tabel, dimana $\mathrm{df}=\mathrm{N}-2$ maka $\mathrm{r}$ tabelnya 0,3172 sedangkan nilai dari sampel pertanyaan mendapatkan nilai $\mathrm{r}$ hitung $=0.778$ lebih besar dari nilai $\mathrm{r}$ tabel $=0,3172$ sehingga pertanyaan tersebut dikatakan Valid.
\end{abstract}

Kata Kunci: Abrasi, Google Earth, Validitas, SPSS, dampak. 


\section{Pendahuluan}

Pesisir adalah suatu daratan di Kawasan tepi laut dan terdapat pengaruh dari laut, diantaranya adalah perembesan laut, pasang surut, dan angin laut [1]. Pesisir dapat memberikan manfaat pada kegiatan manusia diantaranya yaitu pelabuhan, kawasan industri, persawahan, tambak, permukiman dan objek wisata karena kondisi alamnya yang sangat berpotensi untuk kegiatan tersebut.

Abrasi adalah satu dari permasalahan pesisir dan dapat terjadi pengurangan atau pengikisan pantai, merusak petak persawahan yang terdapat di sekitar pinggiran pantai, sehingga dapat berbahaya bagi bangunan yang terdapat pada Batasan daerah laut. Proses pengikisan yang terjadi pada posisi asal pantai dinamakan Abrasi Pantai [1]. Pantai utara pulau jawa adalah pantai yang cukup rawan dikarenakan proses abrasi, dikarenakan pantai tersebut dihadapkan langsung dengan lautan yang luas dan terbuka. Pantai utara pulau jawa mempunyai potensi terjadinya gelombang laut yang tinggi sebagai akibat tiupan angin besar maupun badai yang menerjang kawasan pesisir sehingga dari fenomena tersebut berakibat pada perubahan kondisi pantai, abrasi dan terjadi sedimentasi di tempat - tempat tertentu.Abrasi atau erosi adalah terlepasnya material pantai yang menyebabkan kerusakan-kerusakan yang terjadi di garis pantai, seperti lempung maupun pasir yang terjadi secara terus menerus dan dihantam gelombang laut serta dapat juga disebabkan terjadinya perubahan keseimbangan pada angkutan sedimen yang ada di perairan pantai serta terjadinya hilangnya pada daratan yang terdapat pada wilayah pesisir, sedangkan sendimentasi atau disebut juga akresi merupakan penambahan daratan baru yang terjadi pada wilayah pesisir.

Fenomena akresi serta abrasi dapat terjadi karena faktor alami maupun manusia. Proses hidro oseanografi merupakan proses-proses alami, misalnya dapat terjadi di laut di antaranya adalah perubahan yang terjadi pada pola arus, fenomena pasang surut air laut yang dapat mengakibatkan terjadinya abrasi, serta hempasan gelombang [2]. Dalam pengekstrasian pada perubahan yang terjadi di garis pantai yang dilakukan absorbs gelombang infra merah oleh air, serta mereflektansi jenis Panjang gelombang yang terjadi pada jenis objek tanah maupun vegetasi sangat diperlukan dalam memetakan distribusi perubahan air dan darat untuk menjadikan teknik kombinasi ideal [3].

Pulau Tiban merupakan salah satu objek wisata pantai yang ada di kabupaten Kendal yang berada di atas Sedimentasi pasir laut yang sudah terbentuk sekitar tahun 2013. Objek Wisata ini mulai dikelola oleh Kelompok Sadar Wisata (Pokdarwis) Desa Kartikajaya pada awal tahun 2015 dibawah naungan Dinas Pariwisata Kabupaten Kendal. Untuk mencapai lokasi Objek Wisata Pantai "Pulau Tiban" harus menggunakan armada perahu yang sudah dikelola oleh BUMDes "Sejahtera" yang terbentuk pada tanggal 16 September 2016 oleh Pemerintahan Desa Kartikajaya. Sehingga dari hasil pengelolaan objek wisata tersebut bisa menambah Pendapatan Asli Desa (PAD) Desa Kartikajaya untuk dipergunakan sebesar-besarnya kemakmuran masyarakat setempat.

Pada pertengahan tahun 2017 terjadi badai yang cukup besar serta mengakibatkan abrasi pantai yang besar pula sehingga menghancurkan objek wisata "Pulau Tiban". Pulau kecil dengan luas kurang lebih $75.000 \mathrm{~m}^{2}$ sekarang tinggal hamparan pasir di tepian pantai yang hampir tertutup air laut jika terjadi air pasang, sehingga mengakibatkan aktifitas kepariwisataan menjadi terhenti.Berdasarkan latar belakang, penulis bertujuan untuk melakukan penelitian dampak abrasi terhadap objek wisata "Pulau Tiban” Desa Kartikajaya Kecamatan Patebon Kabupaten Kendal.

\section{Tinjauan Pustaka}

\subsection{Pantai}

Pantai merupakan daerah daratan dan daerah lautan saling bertemu dan aktifitas keduanya saling mempengaruhi satu sama lain. Pantai dapat diartikan sebagai wilayah yang masih dipengaruhi pasang surut air laut hingga wilayah antara garis pantai, serta dibentuk oleh endapan lumpur maupun pasir atau dapat juga berupa kerikil. 


\subsection{Klasifikasi Pantai}

Klasifikasi pantai berdasarkan materi penyusun [1] :

$$
\begin{array}{ll}
\text { - } & \text { Pantai berbatu } \\
\text { - } & \text { Pantai berpasir } \\
\text { - } & \text { Pantai berlumpur. }
\end{array}
$$

\subsection{Karakteristik Pantai}

Peralihan antara daratan dan laut sering disebut pesisir. Pesisir, daratan dan laut (samudra) sudah dikenal luas oleh masyarakat secara umum. Ketiganya memiliki batas berdasarkan sudut pandang dan kegunaannya secara fisik. Proses laut yang mempengaruhi karakteristik pesisir sebagai batas dengan daratan yaitu angin laut, pasang surut dan intrusi garam. Sedangkan proses-proses alami yang mempengaruhi karakteristik pesisir sebagai batas dengan laut sedimentasi dan mengalirnya air tawar ke laut, maupun daerah laut yang dipengaruhi oleh kegiatan-kegiatan manusia di daratan,

Letak daerah perairan Indonesia sangatlah kompleks, karena berada di antara pertemuan antara Samudera Hindia dan Samudera Pasifik. Selain itu, musim di Indonesia juga dipengaruhi oleh Benua Asia dan Benua Australia yang berdampak terhadap sifat-sifat oseanografi perairan Indonesia. Terlebih Indonesia terdiri dari beberapa pulau yang menjadi batas terhadap perairan pedalaman.

\subsection{Ekosistem Pantai}

Dari sekian banyak ekosistem yang terdapat pada pantai khususnya di Indonesia, beberapa yang sering kita jumpai antara lain:

- Hutan Mangrove

Hutan mangrove adalah salah satu hutan hujan tropis yang terdapat di sepanjang garis pantai perairan tropis yang memiliki keunikan tersendiri. Hutan ini merupakan ekosistem utama pendukung kehidupan habitat yang beralih dari lingkungan darat dan laut, sehingga memiliki sifat yang tidak sama seperti sifat-sifat yang dimiliki hutan hujan tropis di daratan.

- Terumbu Karang

Terumbu karang merupakan ekosistem di laut bersel satu yang mempunyai rumah yang terbuat dari kapur berbentuk koloni. Habitatnya hidup di perairan dangkal yang jernih didasar laut daerah tropis dan terbentuk oleh organisme bawah laut penghasil kapur (Ca-karbonat).

Pada Tabel 1 merupakan tolak ukur penilaian kerusakan pantai [4].

\begin{tabular}{ll} 
& \multicolumn{2}{c}{ Tabel 1. Hriteria Tingkat Kerusakan } \\
\hline Ringan & $<0,5 \mathrm{~meter} /$ tahun \\
\hline Sedang & 0,5 hingga 2,0 meter $/$ tahun \\
\hline Berat & 2,0 hingga 5,0 meter $/$ tahun \\
\hline Amat Berat & 5,0 hingga 10,0 meter $/$ tahun \\
\hline Amat Sangat Berat & $>10$ meter $/$ tahun \\
\hline
\end{tabular}

\subsection{Perlindungan Pantai dari Abrasi}

Perlindungan pantai dari abrasi diklasifikasikan menjadi dua [5], yaitu:

a. Perlindungan Alami

- Pantai Pasir

- Pantai Lumpur

- Pantai Karang

b. Perlindungan Buatan

- Dinding Pantai

- Groin

- Jetty

- Pemecah Gelombang 


\subsection{Abrasi}

Abrasi merupakan proses pengikisan atau pengurangan garis pantai yang memiliki karakteristik merusak dan memberikan kerugian terhadap garis pantai menjadi mundur dan daratan menghilang dikarenakan kikisan air laut. Abrasi terjadi karena beberapa faktor diantaranya faktor alam berupa hantaman gelombang laut dan arus laut, dan abrasi juga terjadi karena faktor yang disebabkan oleh aktivitas manusia yaitu merusak atau merugikan seperti pengalihan fungsi lahan mangrove, pengerukan pasir pantai, dan sebagainya

Penyebab atau faktor terjadinya abrasi disebabkan oleh perubahan alam. Ketika angin bergerak di laut, menghasilkan gelombang dan arus laut menuju pantai. Arus angin menuju pantai memiliki kekuatan untuk mengikis pantai secara bertahap. Pada saat yang sama, ombak pantai dapat mengguncang bebatuan yang akan terlepas dari daratan.

Abrasi tersebut disebabkan oleh aktivitas masyarakat di wilayah pesisir, sehingga proses abrasi semakin lama semakin cepat. Dari segi sosial dan ekonomi, wilayah pesisir merupakan wilayah yang sangat dinamis. Faktor manusia dan alam sangat kuat, melahirkan berbagai bentuk kegiatan sosial dan ekonomi. Terdapat beberapa dampak kerusakan fisik yang diakibatkan oleh erosi [6] :

a. Kerusakan fasilitas wisata seperti tempat duduk dan kamar kecil.

b. Akibat pengikisan gelombang yang terus menerus, perubahan dari daratan ke laut atau pergerakan garis pantai, lahan penduduk di wilayah pesisir menjadi semakin sempit.

c. Ancaman terhadap permukiman dari gelombang dan erosi

d. Penumpukan material batuan yang sejajar dengan garis pantai disebabkan oleh material dari daerah lepas pantai yang terbawa oleh gelombang.

e. Jika pantai rusak, bangun bendungan atau pemecah gelombang.

f. Tujuan membangun bangunan pantai adalah untuk menghentikan kecepatan ombak dan melemahkan air yang menerpa pantai, sehingga melindungi pantai dari abrasi yang lebih besar.

\subsection{Penginderaan Jauh}

Suatu usaha yang dilakukan dengan menggunakan sensor secara alamiah ataupun buatan dengan tujuan untuk mengetahui suatu objek sering disebut penginderaan jauh (remote sensing). Sensor alamiah merupakan penginderaan pada tubuh manusia yaitu mata, telinga, kulit, lidah, dan hidung. Sedangkan sensor buatan antara lain kamera, sonar, magnetometer, radiometer, dan scanner.

Penginderaan jauh sebenarnya memperoleh data dan informasi dari objek tanpa menyentuhnya. Definisi yang dikemukakan oleh banyak ahli adalah sebagai berikut:

a. Lindgren: Menggunakan berbagai teknologi penginderaan jauh untuk memperoleh dan menganalisis informasi tentang bumi.

b. Lillesand dan Kiefer: Seni maupun ilmu dalam mendapatkan informasi mengenai objek, area, maupun fenomena melalui analisis data, dan diperoleh dari peralatan perekam yang menggunakan gelombang elektromagnetik sebagai perantara, tanpa menyentuh objek, area, atau fenomena.

Penginderaan jauh bertujuan untuk mengetahui struktur geologi dan jenisnya, memantau daerah bencana, memantau abu vulkanik, memantau sebaran sumber daya alam, memantau pencemaran laut pada reservoir minyak laut, penggunaan di bidang pertahanan dan militer, dan pemantauan permukaan.

\section{Metode}

\subsection{Lokasi Penelitian}

Penelitian ini dilaksanakan di Pantai Pulau Tiban, Desa Kartikajaya, Kecamatan Patebon, Kabupaten Kendal. Pantai yang bertempat di Pulau Tiban adalah pantai yang di apit oleh dua muara sungai besar yaitu sungai Bodri dan sungai Kendal dan tepatnya berada di ujung muara sungai kecil yaitu sungai "Lingen" yang membelah desa Kartikajaya. Sedangkan lokasi Pulau Tiban itu sendiri sebenarnya berada diperbatasan antara Desa Kartika Jaya dan Desa Wonosari sehingga akses untuk mencapai lokasi Wisata Pulau Tiban harus melewati sungai Lingen yang sebagian berada di wilayah administratif Desa Wonosari Kecamatan Patebon. 


\subsection{Waktu Penelitian}

Penelitian ini dilakukan di tahun 2020 hingga tahun 2021, mulai dari tahap perencanaan dan pemilihan judul sampai pengelolaan hasil penelitian.

\subsection{Metode Penelitian}

Metode penelitian ini menggunakan metode Deskriptif Kuantitatif. Deskriptif Kuantitatif dilakukan untuk menganalisis, mendeskripsikan dan menggambarkan data sekunder. Dalam menganalisis aspek fisik berupa gambaran yang jelas mengenai perhitungan laju abrasi dengan menginterpretasikan citra yaitu menggunakan aplikasi Google Earth. Google Earth merupakan sebagai pemantauan yang dapat di lakukan dari jarak jauh untuk mengetahui luasan daerah yang terkena abrasi dari tahun ke tahun..

Sedangkan metode yang digunakan untuk mengetahui dampak abrasi pantai yang menghanguskan Pulau Tiban terhadap mata pencaharian masyarakat sekitar seperti armada perahu, pedagang, dan pelaku pengelola objek wisata. Hal tersebut perlu dilakukan observasi, wawancara dan dokumentasi untuk mengetahui abrasi yang terjadi pada Pantai Pulau Tiban.

\subsection{Teknik Pengambilan Data}

Data Primer, pengambilan data didapatkan melalui survei lokasdi di Pulau Tiban dan wawancara langsung kepada pengelola obyek wisata Pulau Tiban.

Data Sekunder, pengambilan data diperoleh dari peneliti yang turut serta pengelolaan obyek wisata dan dari Badan - Badan pemerintah yang berkaitan dengan penelitian ini seperti :

- BPS Kabupaten Kendal

- PSDA Kabupaten Kendal

- Dinas Pariwisata Kabupaten Kendal

- Pemerintah Desa Kartika Jaya

\subsection{Populasi dan Sampel}

Populasi wilayah yang akan dilakukan penelitian yaitu populasi wilayah Desa Kartikajaya Kecamatan Patebon Kabupaten Kendal, dan populasi masyarakat dilakukan oleh masyarakat di Desa Kartikajaya. Sampel yaitu bagian dari jumlah dan karakteristik yang dimiliki oleh populasi tersebut. Sehingga sampel merupakan bagian populasi yang ada, sehingga dalam pengambilan sampel harus digunakan cara tertentu berdasarkan oleh pertimbangan-pertimbangan [7].

Sampel mempunyai tahapan sebagai berikut:

Tujuan Pengambilan Sampel:

- Populasi mempunyai jangkauan yang sangat luas, sehingga dilakukannya pengambilan data dalam seluruh populasi tidaklah mungkin dapat dilakukan.

- Keterbatasan waktu, biaya, maupun tenaga.

- Terdapat asumsi bahwa seluruh populasi memiliki keseragaman dan dapat digunakan sampel saja.

Tahapan Pengambilan Sampel diantaranya:

- Mendefinisikan populasi yang akan diamati

- Menentukan kerangka sampel dan kumpulan semua peristiwa yang mungkin

- Menentukan teknik atau metode sampling yang tepat

- Melakukan pengambilan sampel (pengumpulan data)

- Melakukan pemeriksaan ulang pada proses sampling 


\subsection{Uji Validitas}

Istilah validitas mendefinisikan ketepatan dan ketelitian alat ukur dalam menjalankan fungsi dimensionalnya [8]. Validitas adalah ukuran yang menunjukkan bahwa variabel yang diukur memang merupakan variabel yang ingin diperiksa oleh peneliti.

Validitas tes angket dibagi menjadi dua, yaitu validitas faktor dan validitas item. Jika beberapa faktor digunakan (ada kesamaan antara satu faktor dengan faktor lainnya) untuk menyusun proyek, efektivitas faktor diukur. Metode untuk mengukur keefektifan faktor ini adalah dengan mengkorelasikan skor faktor (jumlah item dalam suatu faktor) dengan skor faktor total (jumlah semua faktor).

Validitas item menunjukkan terdapat korelasi maupun dukungan item total, dan dalam perhitungan harus dilakukan dengan mengkorelasikan antara skor total item terhadap skor item. Apabila digunakan lebih dari satu faktor, maka pengujian validitas item dengan mengkorelasikan antara skor item dengan skor faktor, dilanjutkan mengkorelasikan antara skor item dengan skor total faktor (penjumlahan dari beberapa faktor).

\section{Rumus Kolerasi 1}

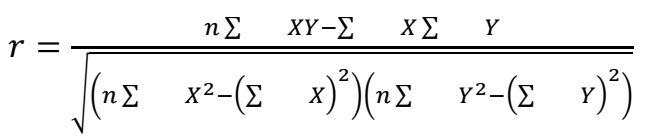

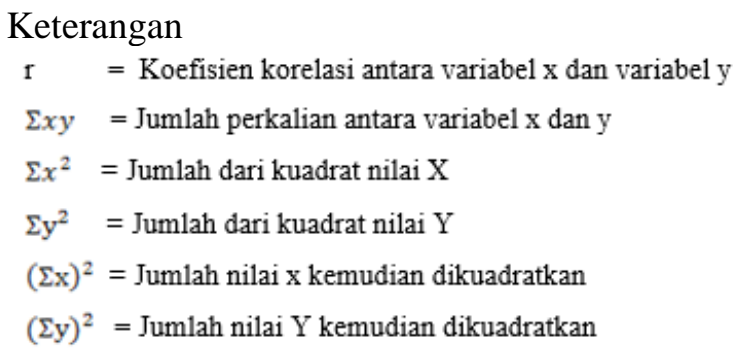

\subsection{Uji Reliabilitas menggunakan SPSS 26.0}

Uji reliabilitas dengan metode tes ulang dilakukan untuk mengetahui bagaimana pengukuran dapat diandalkan. Dalam dilakukannya Uji reliabilitas, pengukuran dilakukan sebanyak dua kali. Pertama pengukuran dan ulangnya, kedua pengukuran dapat dilakukan oleh orang yang sama atau berbeda.

Terdapat Dasar pengambilan keputusan uji reliabilitas, jika nilai Cronbach's Alpha lebih besar dari nilai 0,60 maka kuesioner atau angket dinyatakan reliabel. Kemudian, jika nilai Cronbach's Alpha kurang dari nilai 0,60 maka kuesioner atau angket dinyatakan tidak reliabel.

Reliabilitas Instrumen Uji Coba secara manual.

Rumus :

$$
r 11=\frac{k}{k-1} x\left\{1-\frac{\Sigma S i}{S t}\right\}
$$

Dimana :

r11 = Nilai reliabilitas

$\sum \mathrm{Si}=$ Jumlah varian skor tiap-tiap item

St $\quad=$ Varian total

$\mathrm{k} \quad=$ Jumlah item

Kriteria :

Apabila r11> r tabel, maka dapat disimpulkan bahwa instrumen tersebut reliabel.

Bagian ini berisi metodologi yang digunakan oleh penulis dalam menyelesaikan permasalahan yang diteliti. 


\section{Hasil dan Pembahasan}

\subsection{Penginderaan}

Hasil Pemanfaatan teknologi penginderaan menggunakan software Google Earth untuk mengalanisis citra dari tahun 2010 sampai dengan 2019 dapat diketahui luas lahan di Pulau Tiban Desa Kartikajaya Kecamatan Patebon Kabupaten Kendal. Dari hasil Penelitian tersebut juga dapat diketahui berapa besar luas akresi atau sedimentasi dan juga abrasi pantai ini dari tahun ke tahun.

Dari Gambar di bawah dapat diketahui luasan Pulau Tiban dari tahun 2010 sampai dengan 2019 yang selalu berubah seiring terjadinya akresi, sedimentasi dan abrasi di Pulau Tiban

Berikut data luasan Pulau Tiban dari tahun 2010 hingga tahun 2020.

Tabel 2. Tingkat Akresi dan Abrasi Pulau Tiban

\begin{tabular}{|c|c|c|c|c|c|}
\hline \multirow{2}{*}{ Name } & \multirow{2}{*}{ Year } & \multicolumn{2}{|c|}{ Area } & \multicolumn{2}{|c|}{ Coordinate } \\
\hline & & $\boldsymbol{H a}$ & $m^{2}$ & Latitude & Longitude \\
\hline Pulau Tiban & 2010 & 0 & 0 & -68.653 .697 & 1.102 .142 .136 \\
\hline Pulau Tiban & 2011 & 0 & 0 & -68.653 .697 & 1.102 .142 .136 \\
\hline Pulau Tiban & 2012 & 0.59 & 5900 & -68.653 .697 & 1.102 .142 .136 \\
\hline \multirow[b]{2}{*}{ Pulau Tiban } & & & 1300 & & \\
\hline & 2013 & 1.3 & 0 & -68.653 .697 & 1.102 .142 .136 \\
\hline \multirow{3}{*}{ Pulau Tiban } & & & 1500 & & \\
\hline & 2014 & 1.5 & 0 & -68.653 .697 & 1.102 .142 .136 \\
\hline & & & 6900 & & \\
\hline \multirow[t]{2}{*}{ Pulau Tiban } & 2015 & 6.9 & 0 & -68.653 .697 & 1.102 .142 .136 \\
\hline & & & 5800 & & \\
\hline \multirow[t]{2}{*}{ Pulau Tiban } & 2016 & 5.8 & 0 & -68.653 .697 & 1.102 .142 .136 \\
\hline & & & 8200 & & \\
\hline \multirow[t]{2}{*}{ Pulau Tiban } & 2017 & 8.2 & 0 & -68.653 .697 & 1.102 .142 .136 \\
\hline & & & 4800 & & \\
\hline \multirow[t]{2}{*}{ Pulau Tiban } & 2018 & 4.8 & 0 & -68.653 .697 & 1.102 .142 .136 \\
\hline & & & 3800 & & \\
\hline \multirow{2}{*}{$\begin{array}{l}\text { Pulau Tiban } \\
\text { Pulau Tiban }\end{array}$} & 2019 & 3.8 & 0 & -68.653 .697 & 1.102 .142 .136 \\
\hline & 2020 & 0 & 0 & -68.653 .697 & 1.102 .142 .136 \\
\hline
\end{tabular}

\subsection{Observasi dan Wawancara}

Jumlah kuesioner yang disebar sebanyak tiga puluh lembar yaitu 6,25 \% X 480 yakni jumlah Kepala Keluarga (KK) di Desa Kartikajaya Kecamatan Patebon. Kuesioner tersebut di bagi secara acak kepada masyarakat sekitar dan terutama kepada pelaku usaha agar dapat di simpulkan efek yang benar- benar dirasakan oleh masyarakat misalnya: penurunan pendapatan keluarga, atau hal lain yang ada pengaruhnya terhadap objek wisata Pulau Tiban.

Tabel 3. Deskripsi Data Primer Sampel

\begin{tabular}{clcc}
\hline \multicolumn{4}{c}{ DESKRIPSI DATA } \\
\hline No & Uraian & $\begin{array}{c}\text { Jumlah } \\
\text { Angket }\end{array}$ & $\begin{array}{c}\text { Prosentase } \\
(\mathbf{\%})\end{array}$ \\
\hline 1 & Kuesioner yang disebarkan & 30 & 100 \\
\hline 2 & Kuesioner yang kembali dan diolah & 28 & 93.33 \\
\hline 3 & Kuesioner yang tidak kembali & 2 & 6.67 \\
\hline
\end{tabular}

Responden dalam penelitian ini terdiri dari 30 orang, yakni 2 Orang dari Pemerintah Desa, 3 orang Lembaga Desa, 5 Orang Pelaku Usaha, dan 20 orang dari masyarakat sekitar.

Tabel 4. Deskripsi Data Primer Sampel

\begin{tabular}{cccc}
\hline \multicolumn{4}{c}{ DESKRIPSI DATA } \\
\hline No & Uraian & Jumlah Angket & Prosentase (\%) \\
\hline 1 & Urusan Pemerintah & 2 & 6.67 \\
\hline 2 & Unsur Lembaga Daerah & 3 & 10.00 \\
\hline
\end{tabular}




\begin{tabular}{cccc}
\hline 3 & Unsur Pelaku USaha & 5 & 16.67 \\
\hline 4 & Unsur Masyarakat Sekitar & 20 & 66.67 \\
\hline & & 30 & 100.00 \\
\hline
\end{tabular}

\subsection{Uji Validitas}

Uji validitas berbantuan SPSS 26.0 for windows tahun 2020, tabel kerja teknik validitas dari 28 responden di dapatkan seperti pada data tabulasi pada tabel 4.5 di atas. Berdasarkan hasil uji validitas instrumen yang dirangkum menunjukkan bahwa kuesioner untuk mengukur tingkat pengetahuan dan dampak abrasi serta harapan masyarakat dinyatakan valid atau sesuai dengan kebenaran. Hal ini dibuktikan dengan membandingkan $\mathrm{r}$ hitung dengan Sig 1-tailed. Validitas data dilihat jika $\mathrm{r}$ hitung $\geq$ Sig.1- tailed dengan signifikansi 0,05 atau 5\%. Hasil lengkapnya dapat dilihat pada Tabel 5 dibawah ini:

Tabel 5. Hasil Uji Validitas versi SPSS 26.0

\begin{tabular}{cccccc}
\hline & \multicolumn{5}{c}{ Item-Total Statistics } \\
\hline & $\begin{array}{c}\text { Scale Mean if } \\
\text { Item Deleted }\end{array}$ & $\begin{array}{c}\text { Scale Variance } \\
\text { if Item Deleted }\end{array}$ & $\begin{array}{c}\text { Corrected } \\
\text { Item-Total } \\
\text { Correlation }\end{array}$ & $\begin{array}{c}\text { Cronbach's } \\
\text { Alpha if Item } \\
\text { Deleted }\end{array}$ & \\
\hline Per1 & 35.21 & 16.693 & .666 & .827 & Valid \\
\hline Per2 & 35.29 & 16.730 & .721 & .824 & Valid \\
\hline Per3 & 35.36 & 16.460 & .514 & .840 & Valid \\
\hline Per4 & 35.11 & 16.544 & .638 & .828 & Valid \\
\hline Per5 & 35.54 & 17.888 & .379 & .850 & Valid \\
\hline Per6 & 35.68 & 16.671 & .612 & .831 & Valid \\
\hline Per7 & 35.46 & 17.665 & .466 & .843 & Valid \\
\hline Per8 & 35.68 & 16.819 & .582 & .833 & Valid \\
\hline Per9 & 35.57 & 17.291 & .430 & .847 & Valid \\
\hline Per10 & 35.64 & 15.201 & .599 & .834 & Valid \\
\hline
\end{tabular}

\section{Kesimpulan}

Berdasarkan hasil penelitian yang dilakukan di Objek Wisata Pantai Pulau Tiban Desa Kartikajaya Kecamatan Patebon Kabupaten Kendal dapat disimpulkan sebagai berikut :

- Pantai di Pulau Tiban mengalami perubahan garis pantai yang diakibatkan sedimentasi dan akresi terjadi sejak tahun 2013 sampai tahun 2017 rata-rata per tahun 1.27 ha

- Tingkat abrasi yang terjadi dalam rentang waktu 2017 sampai dengan 2019 dan hampir menenggelamkan Objek Wisata Pantai Pulau Tiban dengan rata-rata per tahun sebesar 2.5 ha.

- Abrasi disebabkan oleh faktor alam yaitu gelombang badai dan tidak adanya bangunan pelindung pantai serta kurangnya tanaman pantai seperti tanaman mangrove.

\section{Referensi}

[1] Triatmodjo, Bambang. 1999. Teknik Pantai. Beta Offset. Yogyakarta -Indonesia.

[2] Munandar dan Kusumawati I. 2017. Studi Analisis Faktor Penyebab dan Penanganan Abrasi Pantai di wilayah Pesisir Aceh Barat. Jurnal Perikanan Tropis. 4 (1) : 47-56.

[3] Kasim, F. 2012. Pendekatan Beberapa Metode dalam Monitoring Perubahan Garis Pantai Menggunakan Dataset Penginderaan Jauh Landsat dan SIG. Jurnal Ilmiah Agropolitan, 5(1), 620-623.

[4] Oki Setyandito, dan Joko Triyanto. 2014. Analisa Erosi dan Perubahan Garis Pantai Pada Pantai Pasir Buatan dan Sekitarnya di Takisung, Propinsi Kalimantan Selatan. Jurnal Teknik Sipil. Vol. $7(1)$

[5] Triatmodjo, Bambang. 2012. Perencanaan Bangunan Pantai. Beta Offset. Yogyakarta Indonesia.

[6] Sofyan A. 2014. Kajian Kerusakan Pantai Akibat Erosi Marin di Wilayah Pesisir Kelurahan 
Kastela Kecamatan Pulau Ternate. Jurnal Geografi, 12 (1) :65.

[7] Sugiyono. 2006. Metode Penelitian Kuantitatif Kualitatif dan R\&D. Alfabeta. BandungIndonesia..

[8] Azwar, Saifudin. 1986. Validitas dan Reliabilitas. Jakarta: Rineka Cipta 